\title{
Managing noncommunicable diseases during the COVID-19 pandemic in Brazil: findings from the PAMPA cohort
}

\author{
Manejo de doenças crônicas não-transmissíveis durante a \\ pandemia de COVID-19: resultados da coorte PAMPA
}

Jayne Santos Leite (https://orcid.org/0000-0002-4612-7301) ${ }^{1}$

Natan Feter (https://orcid.org/0000-0001-6295-9792) 2,3,4

Eduardo Lucia Caputo (https://orcid.org/0000-0002-3515-9308) 3,4

Igor Retzlaff Doring (https://orcid.org/0000-0003-4279-2707) ${ }^{4}$

Júlia Cassuriaga (https://orcid.org/0000-0002-8352-6774) ${ }^{3}$

Felipe Fossati Reichert (https://orcid.org/0000-0002-0951-9875) 3,4

Marcelo Cozzensa da Silva (https://orcid.org/0000-0003-2336-7131) 3,4

Airton José Rombaldi (https://orcid.org/0000-0002-6707-814X) 3,4
${ }^{1}$ Programa de Pós-

Graduação em Ciências da Saúde, Universidade Federal do Rio Grande do Sul. R. Ramiro Barcelos 2400, Campus Saúde. 90035-003 Porto Alegre RS Brasil. leitejs@outlook.com

${ }^{2}$ School of Human Movement and Nutrition Sciences, Universidade de Queensland. Queensland Austrália.

${ }^{3}$ Programa de Pós-

Graduação em Educação Física, Universidade Federal de Pelotas. Pelotas RS Brasil.

${ }^{4}$ Grupo de Pesquisa em Epidemiologia da Atividade Física, Universidade Federal de Pelotas. Pelotas RS Brasil.

\begin{abstract}
The objective was to identify the impact of social distance in the management of noncommunicable diseases (NCD) in the adult population from the state of Rio Grande do Sul, southern Brazil. This is an ambispective, population-based cohort study. Descriptive analysis and Poisson regression models were used and the results were reported as prevalence ratio and $95 \%$ confidence intervals. From a total of 1,288 participants, $43.1 \%$ needed medical care and $28.5 \%$ reported impaired management of NCDs during social distance. Female sex, age between 18 and 30 years old, living in the Serra region (central region of the state), people with depression and multimorbidity were more likely to have impaired management of NCDs. Being physically active reduced the probability of having impaired management of NCD by $15 \%$. Reduced monthly income was associated with the difficulty in accessing prescription medicine and avoidance of seeking in-person medical assistance. Depression was associated with difficulties in accessing medications, while avoidance of seeking in-person medical assistance was more likely for people with multimorbidity, arthritis/arthrosis/fibromyalgia, heart disease, and high cholesterol.
\end{abstract}

Key words COVID-19, Chronic diseases, Health Services Accessibility, Epidemiology
Resumo O objetivo foi identificar o impacto do distanciamento social no manejo das doenças crônicas não transmissiveis (DCNT) na população adulta do estado do Rio Grande do Sul, sul do Brasil. Este é um estudo de coorte ambispectivo de base populacional. Foi utilizada análise descritiva e modelos de regressão de Poisson, os resultados são apresentados em razão de prevalência e intervalos de confiança de 95\%. De um total de 1.288 participantes, $43,1 \%$ necessitaram de cuidados médicos e $28,5 \%$ relataram manejo prejudicado de DCNT durante o distanciamento social. Sexo feminino, idade entre 18 e 30 anos, residente na região da Serra (região central do estado), pessoas com depressão e multimorbidade apresentaram maior chance de manejo prejudicado das DCNT. Ser fisicamente ativo reduziu a probabilidade de ter gerenciamento prejudicado de DCNT em 15\%. A redução da renda mensal esteve associada à dificuldade de acesso a medicamentos prescritos e a deixar de buscar atendimento médico presencial. A depressão foi associada a dificuldades de acesso a medicamentos, enquanto deixar de buscar assistência médica pessoalmente foi mais provável para pessoas com multimorbidade, artrite/artrose/fibromialgia, doenças cardíacas e colesterol alto. Palavras-chave COVID-19, Doença crônica, Acesso aos Serviços de Saúde, Epidemiologia 


\section{Introduction}

Noncommunicable diseases (NCDs) includes long-term conditions such as cardiovascular diseases, cancer, respiratory diseases, and diabetes. NCDs were responsible for $71 \%$ of the 57 million deaths that occurred globally and corresponded to $85 \%$ of premature deaths (30-69 years) in lowand middle-income countries in 2016 ${ }^{1}$. Besides the high prevalence, these diseases have remarkable economic burden on health systems ${ }^{2,3}$.

Alongside with the coronavirus disease pandemic (COVID-19), NCDs require specific care. Indeed, having some NCD increases the risk for serious complications associated with COVID-194. The World Health Organization (WHO) has called for action health agencies to guarantee the maintenance of assistance to people living with NCDs during this pandemic time. In most high-income countries, the COVID-19 preparedness plan included telemedicine to refer patients to specialized health services; while, in upper-middle income countries this strategy was used to refer patients to alternative health services $^{5}$. However, half of the patients with hypertension or diabetes/diabetes-related complications had their treatments partially or completely disrupted during the COVID-19 pandemic.

Notwithstanding the need of the social distancing recommendations to control the COVID- $19^{6}$, these could have an impact on individual health care ${ }^{7}$. People living with NCD need to maintain a routine care, which includes healthy habits, administration of medicines, and regular medical monitoring. Nevertheless, the access and maintenance of healthcare assistance contrast among people from different socioeconomic levels in Brazil, a reality already observed before this pandemic ${ }^{3,8}$.

Even in strong healthcare systems such as in Germany and the United Kingdom, the spike of COVID-19 cases has induced a chaotic scenario with unavailability of intensive care unit beds, mechanical ventilators, and loss of health professionals due to infections ${ }^{9}$. Consequently, people with NCD had their treatment and access to health services impaired since the beginning of pandemic ${ }^{10}$. Therefore, it is urgent to identify the most affected population groups, so health-related decision-making process can be better targeted and then effective. For this reason, this study aimed to identify the impact of social distancing in managing NCDs in an adult population from the Rio Grande do Sul state, the southern Brazilian state.

\section{Methods}

The present study analyzed baseline data from the PAMPA Cohort (Prospective Study About Mental and Physical Health), an ambispective cohort with adults living in the Rio Grande do Sul state, southern Brazil. This cohort was approved by the Ethics and Research Committee of the Faculty of Physical Education of the Federal University of Pelotas. This manuscript addresses issues derived from a more comprehensive study, and full description of sample recruitment and methodology can be found elsewhere ${ }^{11}$. Due to the social distancing, data collection was performed using an online questionnaire via Google ${ }^{\circledR}$ Forms and spread using social networks and contact with health departments using the available communication channels (i.e. e-mail, social media). The recruitment phase lasted from June $22^{\text {nd }}$ to July $23^{\text {rd }}, 2020$. The complete questionnaire assessed sociodemographic characteristics, low back pain, physical activity, depression, anxiety, and memory before and during social distancing and management of NCD during such period. Questions regarding COVID-19 awareness and knowledge were also included.

Using the prevalence of the three primary outcomes of this cohort (i.e., low back pain, depression and anxiety, and access to healthcare system), the required sample size was 1,764 subjects $^{11}$. The inclusion criteria were: a) to be 18 years or over, and b) live in the Rio Grande do Sul state. To identify people with NCD, we used the following multiple-choice question: "Has any doctor already told you that you have...?"12. The options were hypertension, diabetes, cancer, high cholesterol, arthritis/arthrosis/fibromyalgia, asthma/bronchitis, some heart disease, depression, HIV/AIDS, and other. For analyzes purposes, we presented the seven NCDs with the highest prevalence in our sample (depression [32.4\%], hypertension [25.2\%], high cholesterol [24.2\%], asthma/bronchitis [20.6\%], arthritis/arthrosis/ fibromyalgia [12.3\%], diabetes [7.8\%], and heart disease $[4.4 \%]$ ). Other chronic conditions did not reach $3 \%$ of prevalence. We also assessed the prevalence of multimorbidity, calculated as the proportion of participants with two or more coexistent chronic conditions ${ }^{13}$.

\section{Outcomes}

Three outcomes were analyzed in this study: a) Impaired management of NCD, b) Access of medicines, and c) Avoidance to seek health care assistance during the pandemic. 
Impaired management of NCD was assessed by the question "How much did social distancing influence the control of your chronic disorder?". For analyzes purpose the options "Much worse" and "Worsened were merged, the same were made for "Not Change" and "Improved" options.

Access of medicines was evaluated by the question "During social distancing, how would you rate the access to your prescribed medicines?" with the following options: "Easier than before social distancing", "Same as before social distancing", "More difficult than before social distancing” or "I didn't have access". For analyzes purposes, the last two options were grouped and defined as "impaired access to prescribed medicines".

Avoiding to seek healthcare assistance was assessed using the question "During social distancing, have you avoided seeking in-person medical care for an existing health problem even if required?", with "Yes" or "No" as possible answers. In case participant answered yes, the reason for avoiding health assistance was asked.

\section{Exposure variables}

\section{Sociodemographic variables}

Participants were asked about their gender (male, female), age, skin color (white, black, mixed, yellow or indigenous), highest educational achievement (high school or lower, university degree [graduated], and postgraduate [Specialization, Master, $\mathrm{PhD}]$ ), and marital status (living with a partner [Yes/No]). Additionally, the city where the participant lived was assessed to stratify our sample by regions of Rio Grande do Sul state (Sul, Metropolitana, Norte, Centro-Oeste, Vales, Serra, and Missioneira [in Portuguese]).

\section{Anthropometric and nutritional variables}

Body weight and height were self-reported for later determination of the body mass index (BMI). Participants were classified with either normal $\left(\mathrm{BMI}<25 \mathrm{~kg} / \mathrm{m}^{2}\right)$ or overweight/obese $\left(\mathrm{BMI} \geq 25 \mathrm{~kg} / \mathrm{m}^{2}\right)^{14}$.

\section{Physical activity}

Physical activity during the social distancing was also determined. First, participants were asked: "During social distancing, did you regularly engage in physical activities?". If the answer was "Yes", the number of days and minutes of practice were asked. Physical activity was then calculated multiplying the number of days by the time of practice in each day, and participants were further classified as physically inactive (i.e., less than 150 minutes per week) or active (i.e., 150 minutes or more per week $)^{15}$.

\section{COVID-19 information}

We investigated the participants' self-rated knowledge about the new coronavirus (SARSCoV-2), with options ranging from poor to very good/excellent. Reduced working hours since social distancing was calculated using the difference of "What was your weekly working hours before social distancing?" and "What was your weekly working hours during social distancing?". Decreased monthly income since social distancing was assessed by the question "Did social distancing affect your monthly income?"; yes (reduced), no, yes (increased) were the options. Furthermore, daily routine during social distancing was asked by the following question: "How has your daily routine at home been?". Answering options were: "staying at home all the time", "go out only for essential things" (e.g. buying food, go out sometimes to shopping and stretching my legs), "go out every day for some activity", or "go out every day to work or another regular activity". The two latest alternatives were merged for analyzes purposes.

\section{Statistical analysis}

During data analyzes, we used sampling weight due to heightened proportion of respondents from a specific region of the state (Sul [53.7\%]). Descriptive analyzes were presented as proportion or mean and $95 \%$ confidence interval (CI) as appropriate. Skin colors black, mixed, yellow, and indigenous were clustered due to their low prevalence and named as non-white group. Poisson regression models were used for all three outcomes. For impaired management of chronic disease during the COVID-19 pandemic, analyzes were adjusted for sex, age, skin color, marital status, highest educational achievement, BMI, regular use of prescribed medicine, physical activity status, daily routine during social distancing, changing in working hours, and knowledge about the COVID-19 pandemic. For impaired access to prescribed medicines and avoiding to seek healthcare assistance, analyzes were adjusted for sex, age, skin color, marital status, highest educational achievement, region, daily routine during social distancing, and economic impact of COVID-19 pandemic. The level of significance was 0.05 . 


\section{Results}

A total of 2,321 people participated in the baseline of the PAMPA Cohort. As described in Table 1, participants with any NCD were older (mean age 41.2 [95\%CI: 40.2, 42.2] years) and overweight or obese (59.6 [95\%CI: 56.2, 62.9]) compared to excluded participants. As expected, included participants were more likely to use medicines regularly (57.9\% [95\%CI: $54.5 \%, 61.2 \%]$ ), and require healthcare assistance during social distancing (43.1\% [95\%CI: 39.7\%, 46.5\%]), when compared with participants without NCD, $3.7 \%$ (95\%CI: $2.4 \%, 5.6 \%)$ and $29.3 \%$ (95\%CI: $25.8 \%, 33.0 \%)$, respectively. On the other hand, they were more likely to avoiding to seek healthcare assistance during social distancing $(42.1 \%$ [95\%CI: 37.1\%, 47.3\%]) when compared with people without NCDs (28.1\% [95\%CI: $21.9 \%$, $35.2 \%]$ ). Impaired management of NCD during social distancing was reported by $28.5 \%(95 \% \mathrm{CI}$ : $25.5 \%, 31.6 \%)$ of our sample.

Table 2 summarizes the characteristics of the included participants. Only respondents with medical diagnosis of any NCD were included in the present study $(\mathrm{n}=1,288)$. Most participants were white (91.7\% [95\%CI: 89.6\%, 93.3\%]), lived with a partner $(63.1 \%$ [95\%CI: $59.8 \%$,
$66.3 \%])$, and were physically inactive during social distancing (76.3\% [95\%CI: 73.2\%, 79.1\%]). When analyzed by gender, women reported more cases of reduced working hours since social distancing $(45.3 \%$ [95\%CI: $40.9 \%, 49.7 \%])$ and depression (34.3\% [95\%CI: $30.8 \%, 38.0 \%])$ than men. On the other hand, overweight or obesity (71.9\% [95\%CI: 64.7\%, 78.2\%]) and hypertension $(35.6 \%$ [95\%CI: $28.9 \%, 43.0 \%])$ were higher in men.

Figure 1A illustrated that $43.1 \%$ (95\%CI: $39.7 \% ; 46.5 \%)$ of participants needed some healthcare service during social distancing, with higher proportion among people with depression (58.2\% [95\%CI: 52.3\%, 63.9\%]) and multimorbidity (52.3\% [95\%IC 47.0\%, 57.5\%]). Figure 1B showed most participants preferred in-person healthcare assistance during social distancing (85\% [95\%CI: 80.7\%, 88.5\%]). However, people with asthma/bronchitis (23.4\% [95\%CI: $12.7 \%$, $39.1 \%])$, high cholesterol $(21.7 \% \quad$ [95\%CI: $12.2 \%, 35.7 \%]$ ), and arthritis/arthrosis/fibromyalgia (20.6\% [95\%CI: 8.6\%, 41.7\%]) reported seek more for virtual healthcare assistance, compared to participants with other NCDs. The most common reasons for seeking health services were pre-existing health problem $(26.9 \%)$, other reasons $(22.8 \%)$, scheduled return $(15.3 \%)$, vac-

Table 1. Characteristics of participants excluded and included based on diagnostic of noncommunicable diseases. Rio Grande do Sul, Brazil, 2020 (N=2,321).

\begin{tabular}{|c|c|c|c|}
\hline & \multirow{2}{*}{$\begin{array}{c}\text { Overall } \\
(\mathrm{n}=2,321)\end{array}$} & \multicolumn{2}{|c|}{ Noncommunicable disease } \\
\hline & & No $(n=1,033)$ & Yes $(n=1,288)$ \\
\hline Age (mean, 95\%CI) & $38.2(37.5,38.9)$ & $34.2(33.3,35.1)$ & $41.2(40.2,42.2)$ \\
\hline Skin color, white $(\%, 95 \% \mathrm{CI})$ & $76.6(74.4,78.7)$ & $89.2(86.6,91.4)$ & $91.7(89.6,93.3)$ \\
\hline $\begin{array}{l}\text { Highest educational achievement, high school (\%, } \\
95 \% \mathrm{CI})\end{array}$ & $90.6(89.0,92.0)$ & $36.2(32.6,40.0)$ & $31.1(28.0,34.4)$ \\
\hline Living with partner $(\%, 95 \% \mathrm{CI})$ & $33.3(30.9,35.8)$ & $59.6(55.8,63.3)$ & $63.1(59.8,66.3)$ \\
\hline Overweight or obese $(\%, 95 \% \mathrm{CI})$ & $61.6(59.1,64.0)$ & $44.9(41.1,48.8)$ & $59.6(56.2,62.9)$ \\
\hline Physical activity, inactive $(\%, 95 \% \mathrm{CI})$ & $53.3(50.7,55.8)$ & $72.2(68.7,75.5)$ & $76.3(73.3,79.1)$ \\
\hline $\begin{array}{l}\text { Knowledge about COVID-19, very good/excellent } \\
(\%, 95 \% \text { CI })\end{array}$ & $74.5(72.3,76.7)$ & $52.0(48.1,55.8)$ & $55.1(51.7,58.5)$ \\
\hline $\begin{array}{l}\text { Reduced working hours since social distancing } \\
(\%, 95 \% \mathrm{CI})\end{array}$ & $53.7(51.2,56.3)$ & $44.3(40.0,48.7)$ & $43.1(39.2,47.0)$ \\
\hline $\begin{array}{l}\text { Decreased monthly income since social distancing } \\
(\%, 95 \% \mathrm{CI})\end{array}$ & $43.6(40.7,46.5)$ & $48.9(45.0,52.7)$ & $42.5(39.2,45.9)$ \\
\hline Regular use of prescribed medicine $(\%, 95 \% \mathrm{CI})$ & $45.3(42.7,47.8)$ & $3.7(2.4,5.6)$ & $57.9(54.5,61.2)$ \\
\hline $\begin{array}{l}\text { Access to prescribed medicines during social distancing, } \\
\text { impaired }(\%, 95 \% \mathrm{CI})\end{array}$ & $34.5(32.1,37.0)$ & $36.4(18.9,58.3)$ & $17.9(14.7,21.6)$ \\
\hline $\begin{array}{l}\text { Required healthcare services during social distancing } \\
(\%, 95 \% \mathrm{CI})\end{array}$ & $18.7(15.5,22.4)$ & $29.3(25.8,33.0)$ & $43.1(39.7,46.5)$ \\
\hline Avoiding to seek healthcare assistance $(\%, 95 \% \mathrm{CI})$ & $37.1(34.7,39.4)$ & $28.1(21.9,35.2)$ & $42.1(37.1,47.3)$ \\
\hline
\end{tabular}


Table 2. Characteristics of participants diagnosed with noncommunicable disease by sex. Rio Grande do Sul, Brazil, $2020(\mathrm{~N}=1,288)$.

\begin{tabular}{|c|c|c|c|}
\hline & \multirow{2}{*}{$\begin{array}{c}\text { Overall } \\
(\mathrm{n}=1,288)\end{array}$} & \multicolumn{2}{|c|}{ Sex } \\
\hline & & Male $(n=258)$ & $\begin{array}{c}\text { Female } \\
(\mathbf{n}=1,030)\end{array}$ \\
\hline Age (mean, 95\%CI) & $41.5(40.7,42.3)$ & $39.5(37.5,41.5)$ & $41.6(40.5,42.7)$ \\
\hline Skin color, white $(\%, 95 \% \mathrm{CI})$ & $91.7(89.6,93.3)$ & $88.9(83.1,92.9)$ & $92.4(90.2,94.1)$ \\
\hline $\begin{array}{l}\text { Highest educational achievement, high school (\%, } \\
95 \% \mathrm{CI})\end{array}$ & $31.1(28.0,34.4)$ & $34.5(27.8,42.0)$ & $30.2(26.8,33.9)$ \\
\hline Living with partner $(\%, 95 \% \mathrm{CI})$ & $63.1(59.8,66.3)$ & $62.5(55.0,69.4)$ & $63.3(59.2,66.9)$ \\
\hline Overweight or obese $(\%, 95 \% \mathrm{CI})$ & $59.6(56.2,62.9)$ & $71.9(64.7,78.2)$ & $56.4(52.5,60.2)$ \\
\hline Physical activity, inactive $(\%, 95 \% \mathrm{CI})$ & $76.3(73.2,79.1)$ & $73.3(66.1,79.3)$ & $77.1(73.7,80.2)$ \\
\hline $\begin{array}{l}\text { Knowledge about COVID-19, very good/excellent } \\
(\%, 95 \% \mathrm{CI})\end{array}$ & $55.1(51.7,58.5)$ & $58.1(50.6,65.2)$ & $54.3(50.5,58.1)$ \\
\hline $\begin{array}{l}\text { Reduced working hours since social distancing } \\
(\%, 95 \% \mathrm{CI})\end{array}$ & $43.1(39.2,47.0)$ & $34.3(26.6,42.9)$ & $45.3(40.9,49.7)$ \\
\hline $\begin{array}{l}\text { Decreased monthly income since social distancing } \\
(\%, 95 \% \mathrm{CI})\end{array}$ & $42.5(39.2,45.9)$ & $41.9(34.8,49.4)$ & $42.7(38.9,46.5)$ \\
\hline Regular use of prescribed medicine $(\%, 95 \% \mathrm{CI})$ & $57.9(54.5,61.2)$ & $55.7(48.2,63.0)$ & $58.4(54.6,62.2)$ \\
\hline $\begin{array}{l}\text { Access to prescribed medicines during social distancing, } \\
\text { impaired }(\%, 95 \% \mathrm{CI})\end{array}$ & $17.9(14.7,21.6)$ & $19.9(12.9,29.5)$ & $17.4(13.9,21.5)$ \\
\hline $\begin{array}{l}\text { Required healthcare services during social distancing } \\
(\%, 95 \% \mathrm{CI})\end{array}$ & $43.1(39.7,46.5)$ & $40.2(33.0,47.8)$ & $43.8(40.1,47.7)$ \\
\hline Avoiding to seek healthcare assistance $(\%, 95 \% \mathrm{CI})$ & $42.2(37.1,47.4)$ & $49.7(37.8,61.6)$ & $40.4(34.9,46.1)$ \\
\hline Depression $(\%, 95 \% \mathrm{CI})$ & $32.4(29.3,35.7)$ & $25.5(19.5,32.6)$ & $34.3(30.8,38.0)$ \\
\hline Hypertension $(\%, 95 \% \mathrm{CI})$ & $25.2(22.4,28.3)$ & $35.6(28.9,43.0)$ & $22.5(19.5,25.8)$ \\
\hline High cholesterol (\%, 95\%CI) & $24.2(21.4,27.3)$ & $27.3(21.1,34.5)$ & $23.4(20.3,26.9)$ \\
\hline Multimorbidity (\%, 95\%CI) & $23.3(21.1,25.4)$ & $19.5(15.7,24.1)$ & $24.4(21.9,26.9)$ \\
\hline Asthma/bronchitis $(\%, 95 \% \mathrm{CI})$ & $20.6(17.9,23.5)$ & $20.1(14.9,26.7)$ & $20.7(17.7,24.0)$ \\
\hline Diabetes $(\%, 95 \% \mathrm{CI})$ & $7.8(6.2,9.7)$ & $9.3(5.9,14.5)$ & $7.3(5.7,9.5)$ \\
\hline Heart disease $(\%, 95 \% \mathrm{CI})$ & $4.4(3.2,6.0)$ & $2.2(0.9,5.0)$ & $5.0(3.5,7.0)$ \\
\hline
\end{tabular}

Values are reported as proportions and $95 \%$ confidence intervals.

cination $(13.3 \%)$, to get medicine $(11.0 \%)$, and due to flu symptoms or sore throat $(5.1 \%)$.

Table 3 shows the crude and adjusted analyzes about impaired management of NCD during social distancing. The probability of such event was $49 \%$ greater in women than men and $22 \%$ higher in adults aged 31-50 than those aged between 18 and 30 years old. Participants who lived in the Serra region had a probability $55 \%$ greater than participants from the Sul region to have impaired management of NCD. Also, people with impaired access to prescribed medicine had a probability 99\% greater of uncontrolled NCD than those who had access to medicines. Being considered physically active during social distancing reduced in $15 \%$ the probability of having impaired management of NCD during the same period when compared to inactive participants.
Table 4 shows the factors associated with impaired access to prescribed medicines during social distancing. Our findings revealed that participants with university degree or post-graduate (specialization, Master, or Ph.D.) were 51\% and $54 \%$, respectively less likely to report impaired access to prescribed medicines during social distancing when compared with participants with less schooling. However, respondents with reduced monthly income had a probability $49 \%$ higher to impaired access to medicine during the same period.

Avoidance of seeking healthcare assistance during social distancing was reported by $42.1 \%$ (95\%CI: $37.1 \%, 47.3 \%$ ) of our sample, and the main reason for this was the fear of being contaminated by new coronavirus $(77.4 \%$ [95\%CI: $70.2 \%, 83.3 \%]$ ). Table 5 shows that participants 


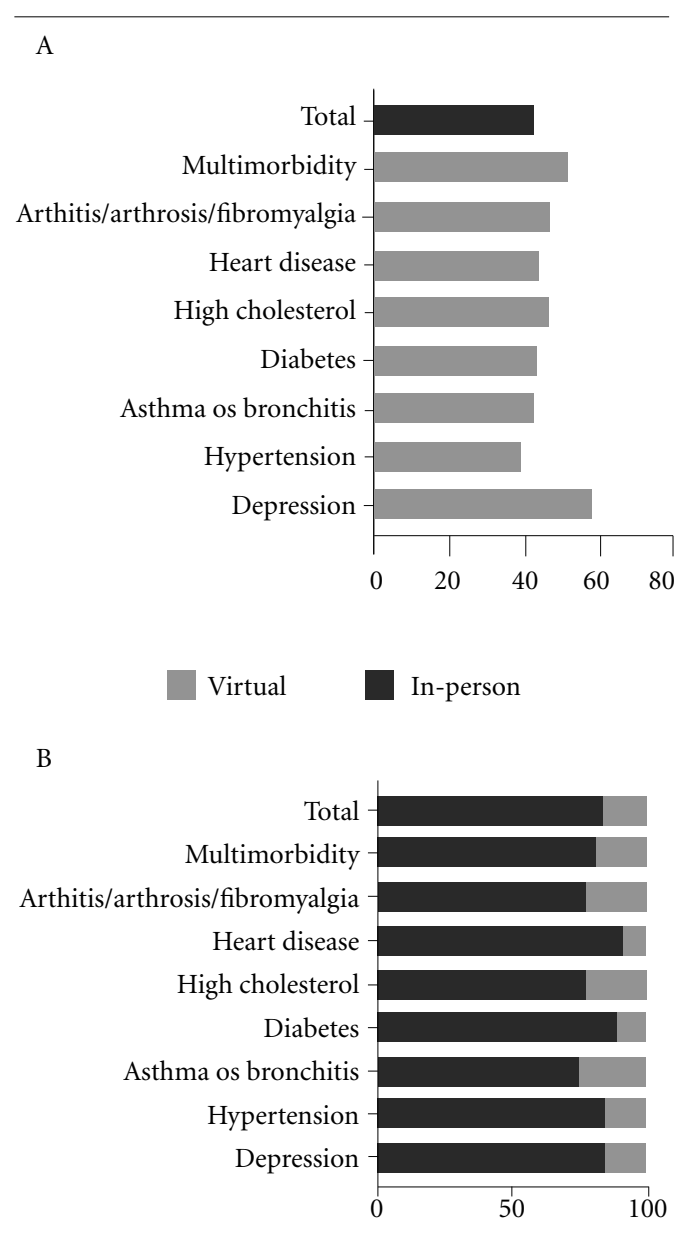

Figure 1. Requirement (A) and type (B) of healthcare assistance used during social distancing by noncommunicable disease among people with NCD. Rio Grande do Sul, Brazil, 2020 (N=1,288).

with specialization, Master, or Ph.D. degree were less likely (38\%) to avoid seeking healthcare assistance during social distancing. On the other hand, reduced monthly income during such period increased in $44 \%$ the likelihood of avoiding to seek healthcare.

Figure 2 illustrates the prevalence ratio ( $95 \% \mathrm{CI})$ of (A) impaired management of NCD, (B) impaired access to prescribed medicines, and (C) avoid medical assistance. Participants with multimorbidity and depression were more likely to have impaired management of NCD than their counterparts. Also, participants with depression showed higher probability to have impaired access to prescribed medicines during social distancing, while people with multimorbidity, arthritis/arthrosis/fibromyalgia, heart dis- ease, and high cholesterol had higher probability of avoiding in-person health assistance.

\section{Discussion}

This study aimed to verify the impact of social distancing in the health of people with NCD in the southern state of Brazil. Our findings indicate that women, young adults (i.e., 18-30 years), those who lived at the Serra region, had impaired access to prescribed medicines, and had depression and multimorbidity were at higher risk of having impaired management of their NCD. Participants with depression were more likely to have impaired access to prescribed medicine. Further, participants with multimorbidity, arthritis/arthrosis/fibromyalgia, and high cholesterol had higher probability to avoid seeking in-person healthcare services even if required during social distancing.

We revealed that young adults and women were more likely to worsen management of their chronic conditions. Impaired management of NCD in women might be associated with the double workload during social distancing. Besides job-related working hours spent at home, it is known that due to gender inequality in households activities, women are spending more time at home in tasks such as providing care for people with chronic disability and in school-related activities from children ${ }^{16}$. This double workload may lead to an overload in physical and mental health, impairing the management of pre-existent conditions during the COVID-19 pandemic $^{17}$. Mássimo et al. ${ }^{18}$ showed that young adults have lower adherence to self-care, indicating that this behavior tends to change with age progression. Consequently, an improved knowledge of how important is to have a better health management is observed as people get old.

The Rio Grande do Sul government developed a controlled social distancing system based on the incidence of COVID-19 cases, hospital beds availability, and number of deaths in each the macroregion ${ }^{19}$. Each region within the state was classified into four possible flags (i.e., yellow, orange, red, black [crescent restriction order]) that indicated the stage and necessary approaches to contain the spread of the virus. Regions in the "red flag", for example, must have their non-essential commercial activities closed, such as shopping malls, stores, restaurants, gyms, and theaters. People living in the Serra region, the central region of the state, were more likely to 
Table 3. Crude and adjusted regression analyses between impaired management of noncommunicable diseases during the COVID-19 pandemic and independent variables in adults with diagnosed noncommunicable diseases. Rio Grande do Sul, Brazil, 2020 (N=1,288).

\begin{tabular}{|c|c|c|c|c|}
\hline & \multicolumn{2}{|l|}{ Crude } & \multicolumn{2}{|c|}{ Adjusted } \\
\hline & $\mathrm{RP}(95 \% \mathrm{CI})$ & p-value & $\mathrm{RP}(95 \% \mathrm{CI})$ & p-value \\
\hline Sex & & 0.015 & & 0.024 \\
\hline Male & 1.00 & & 1.00 & \\
\hline Female & $1.52(1.08,2.13)$ & & $1.49(1.05,2.10)$ & \\
\hline Age, years & & $0.039^{\#}$ & & $0.032^{\#}$ \\
\hline $18-30$ & 1.00 & & 1.00 & \\
\hline $31-59$ & $0.78(0.61,1.00)$ & & $0.78(0.61,0.98)$ & \\
\hline $60+$ & $0.70(0.46,1.07)$ & & $0.69(0.45,1.07)$ & \\
\hline Skin color & & 0.286 & & 0.310 \\
\hline White & 1.00 & & 1.00 & \\
\hline Non-white & $0.78(0.49,1.23)$ & & $0.78(0.49,1.25)$ & \\
\hline Highest educational achievement & & $0.348^{\#}$ & & $0.306^{\#}$ \\
\hline High school or less & 1.00 & & 1.00 & \\
\hline University & $0.82(0.60,1.11)$ & & $1.07(0.44,2.61)$ & \\
\hline Specialization, Master, $\mathrm{PhD}$ & $0.89(0.69,1.16)$ & & $0.89(0.38,2.08)$ & \\
\hline Conjugal status & & 0.047 & & 0.211 \\
\hline With partner & 1.00 & & 1.00 & \\
\hline No partner & $1.26(1.00,1.59)$ & & $1.17(0.91,1.49)$ & \\
\hline Region & & $0.014^{\#}$ & & $0.008^{\#}$ \\
\hline Sul & 1.00 & & 1.00 & \\
\hline Centro-Oeste & $0.82(0.58,1.16)$ & & $0.80(0.54,1.18)$ & \\
\hline Norte & $0.31(0.11,0.92)$ & & $0.28(0.07,1.11)$ & \\
\hline Missioneira & $0.54(0.24,1.20)$ & & $0.72(0.33,1.59)$ & \\
\hline Metropolitana & $0.84(0.69,1.03)$ & & $0.94(0.76,1.16)$ & \\
\hline Vales & $0.78(0.52,1.18)$ & & $0.59(0.34,1.02)$ & \\
\hline Serra & $1.41(1.00,2.00)$ & & $1.55(1.11,2.15)$ & \\
\hline Body mass index & & 0.317 & & 0.950 \\
\hline Normal & 1.00 & & 1.00 & \\
\hline Overweight/obese & $0.89(0.71,1.12)$ & & $0.99(0.78,1.26)$ & \\
\hline Physical activity & & 0.126 & & 0.023 \\
\hline Inactive & 1.00 & & 1.00 & \\
\hline Active & $0.89(0.77,1.03)$ & & $0.85(0.74,0.98)$ & \\
\hline
\end{tabular}

have an impaired NCD management. This region was under the second-highest degree of social distance ("red flag") during three of the four weeks of recruitment phase of this study. On the other hand, the Sul region (reference group) was at yellow and orange flag during the data collection due to lower number of cases and higher hospital beds availability. Our results suggest that less flexible measures for controlling the coronavirus spread must be followed by strategies to assist people with NCD; otherwise, the country may face an increasingly number of preventable hospitalizations and deaths related to chronic health condition. However, the impaired management of NCDs in this region may be associated with other factors such as infrastructure and access to health services specific to Serra region during COVID-19 pandemic.

Physical activity has been recommended to prevent and treat NCDs, thus such behavior is essential for a better clinical control of health conditions $^{20,21}$. We observed that those who were physically active during social distancing had better management of their NCDs. This result reinforces the importance of physical activity promotion to reduce the physical and mental 
Table 3. Crude and adjusted regression analyses between impaired management of noncommunicable diseases during the COVID-19 pandemic and independent variables in adults with diagnosed noncommunicable diseases. Rio Grande do Sul, Brazil, 2020 (N=1,288).

\begin{tabular}{|c|c|c|c|c|}
\hline & \multicolumn{2}{|l|}{ Crude } & \multicolumn{2}{|c|}{ Adjusted } \\
\hline & $\mathrm{RP}(95 \% \mathrm{CI})$ & p-value & $\mathrm{RP}(95 \% \mathrm{CI})$ & p-value \\
\hline \multirow[t]{2}{*}{ Knowledge about COVID-19 } & & 0.590 & & 0.533 \\
\hline & & 0.479 & & 0.250 \\
\hline Regular & 1.00 & & 1.00 & \\
\hline Bad & $1.06(0.34,3.34)$ & & $0.19(0.22,1.67)$ & \\
\hline Good & $0.74(0.49,1.10)$ & & $0.75(0.47,1.19)$ & \\
\hline Very good/ excellent & $0.80(0.55,1.18)$ & & $0.75(0.50,1.11)$ & \\
\hline Change in working hours & & 0.964 & & 0.704 \\
\hline Reduced & $1.04(0.77,1.39)$ & & $1.06(0.76,1.49)$ & \\
\hline Increased & $1.05(0.70,1.57)$ & & $1.24(0.75,2.07)$ & \\
\hline Impaired access to prescribed medicine & & $<0.001$ & & $<0.001$ \\
\hline No & 1.00 & & 1.00 & \\
\hline Yes & $1.94(1.48,2.56)$ & & $1.99(1.44,2.75)$ & \\
\hline Reduced monthly income & & 0.086 & & 0.868 \\
\hline No & 1.00 & & 1.00 & \\
\hline Yes & $1.22(0.97,1.54)$ & & $1.03(0.67,1.60)$ & \\
\hline Routine & & 0.931 & & 0.989 \\
\hline Low & $1.05(0.69,1.60)$ & & $1.01(0.67,1.53)$ & \\
\hline Medium & 1.00 & & 1.00 & \\
\hline High & $1.00(0.63,1.59)$ & & $0.99(0.63,1.56)$ & \\
\hline
\end{tabular}

health burden of people with NCD during social distancing ${ }^{22,23}$.

Participants with depression, which was the most prevalent NCD in our sample, and multimorbidity had worsen management of their chronic condition and more difficulty in accessing prescribed medication. The Rio Grande do Sul state has the highest prevalence of depression in the country, with proportion of cases 2.3 times greater than the national average ${ }^{24}$. People living with depression could be affected by this pandemic by heightened symptoms like fear, insecurity, and loneliness ${ }^{25}$. Likewise, people with multimorbidity could feel more vulnerability and fear considering that having a NCD is a risk factor to poor prognosis of COVID-194. These findings reinforce the need for attention to the physical and mental impact of the COVID-19 pandemic in the population's health. As advocated by the World Health Organization since the beginning of the COVID-19 pandemic, providing continuous treatment and health services for people with NCD must be one of the priorities during this health crisis $^{17}$ especially for people with mental disorders ${ }^{26}$ and multimorbidity ${ }^{27,28}$.

Also, we revealed that people living with depression, high cholesterol, or diabetes were more likely to require healthcare services during social distancing supporting the need to keep these services to people with NCDs during the COVID-19 pandemic ${ }^{29}$. WHO reported that this health crisis impacted health services worldwide, and consequently this fact had some immediate and short-term negative impact on people living with $\mathrm{NCD}^{10}$. Most of participants used in-person healthcare services. Further, 16.7\% used virtual medical assistance, with higher proportion of people with asthma/bronchitis, high cholesterol, and arthritis/arthrosis/fibromyalgia. New forms to access healthcare services must be developed and improved in order to overcome social distancing, and request for investments in telemedicine and e-Health to supply these population in a remote form providing adequate assistance, continue medicine treatment, and avoiding unnecessary visit to health services ${ }^{10,30}$.

Our findings indicate that acute economic strain was associated with impaired access to pre- 
Table 4. Crude and adjusted regression analyses between impaired access to prescribed medicine during the COVID-19 pandemic and independent variables in adults diagnosed with noncommunicable diseases. Rio Grande do Sul, Brazil, $2020(\mathrm{~N}=1,288)$.

\begin{tabular}{|c|c|c|c|c|}
\hline & \multicolumn{2}{|c|}{ Crude } & \multicolumn{2}{|c|}{ Adjusted } \\
\hline & $\mathrm{RP}(95 \% \mathrm{CI})$ & p-value & $\mathrm{RP}(95 \% \mathrm{CI})$ & p-value \\
\hline Sex & & 0.569 & & 0.469 \\
\hline Male & 1.00 & & 1.00 & \\
\hline Female & $0.87(0.54,1.39)$ & & $0.84(0.53,1.34)$ & \\
\hline Age, years & & $0.051^{\#}$ & & $0.184^{\#}$ \\
\hline $18-30$ & 1.00 & & 1.00 & \\
\hline $31-59$ & $0.81(0.53,1.23)$ & & $1.00(0.65,1.55)$ & \\
\hline $60+$ & $0.51(0.25,1.05)$ & & $0.61(0.30,1.23)$ & \\
\hline Skin color & & 0.679 & & 0.483 \\
\hline White & 1.00 & & 1.00 & \\
\hline Non-white & $0.85(0.41,1.80)$ & & $0.77(0.36,1.61)$ & \\
\hline Highest educational achievement & & $<0.001^{\#}$ & & $0.001^{\#}$ \\
\hline High school or less & 1.00 & & 1.00 & \\
\hline University & $0.49(0.29,0.81)$ & & $0.49(0.29,0.81)$ & \\
\hline Specialization, Master, $\mathrm{PhD}$ & $0.48(0.31,0.74)$ & & $0.46(0.29,0.74)$ & \\
\hline Conjugal status & & 0.750 & & 0.879 \\
\hline With partner & 1.00 & & 1.00 & \\
\hline No partner & $1.07(0.71,1.59)$ & & $1.03(0.69,1.54)$ & \\
\hline Region & & 0.918 & & 0.897 \\
\hline Sul & 1.00 & & 1.00 & \\
\hline Centro-Oeste & $0.87(0.45,1.71)$ & & $0.93(0.48,1.79)$ & \\
\hline Norte & $0.41(0.06,2.72)$ & & $0.52(0.08,3.42)$ & \\
\hline Missioneira & $0.81(0.22,2.98)$ & & $0.80(0.22,2.87)$ & \\
\hline Metropolitana & $1.01(0.71,1.43)$ & & $0.97(0.68,1.38)$ & \\
\hline Vales & $1.09(0.48,2.47)$ & & $1.05(0.45,2.46)$ & \\
\hline Serra & $1.42(0.65,3.13)$ & & $1.58(0.75,3.34)$ & \\
\hline Reduced monthly income & & 0.014 & & 0.042 \\
\hline No & 1.00 & & 1.00 & \\
\hline Yes & $1.62(1.11,2.38)$ & & $1.49(1.01,2.18)$ & \\
\hline Routine & & 0.899 & & 0.836 \\
\hline Low & $0.88(0.48,1.62)$ & & $0.86(0.53,1.41)$ & \\
\hline Medium & 1.00 & & 1.00 & \\
\hline High & $0.95(0.49,1.85)$ & & $0.87(0.49,1.54)$ & \\
\hline
\end{tabular}

scribed medicine and avoided seeking healthcare assistance. Decreased monthly income since social distancing has been widely reported as other indirect effect of the COVID-19 pandemic ${ }^{31}$. Combined with abruptly changes in daily routine, financial concern might affect mental and physical health ${ }^{25,32}$. Also, impaired access to medicines may result in disrupted disease treatment and poor disease control ${ }^{33}$, increasing the risk for preventable hospitalizations, disease complications, and death ${ }^{34}$. Further, financial loss could reduce the opportunity to healthy behaviors such as better diet and physical activity, and promoting psychological effects that might consequently impact the control of pre-existent conditions. Access to medicines is a determining factor for correct control of any NCD. It is noteworthy, however, that access to medication treatment for depression, previously the pandemic was already compromised in Brazil ${ }^{35}$.

Avoid seeking healthcare assistance was higher in people living with multimorbidity, high cholesterol, arthritis/arthrosis/fibromyalgia, and heart disease with fear of contagious as the most 
Table 5. Crude and adjusted regression analyses between avoiding to seek healthcare assistance in-person during the COVID-19 pandemic and independent variables in adults diagnosed with noncommunicable diseases. Rio Grande do Sul, Brazil, 2020 (N=1,288).

\begin{tabular}{|c|c|c|c|c|}
\hline & \multicolumn{2}{|l|}{ Crude } & \multicolumn{2}{|c|}{ Adjusted } \\
\hline & $\mathrm{RP}(95 \% \mathrm{CI})$ & p-value & $\mathrm{RP}(95 \% \mathrm{CI})$ & p-value \\
\hline Sex & & 0.149 & & 0.205 \\
\hline Male & 1.00 & & 1.00 & \\
\hline Female & $0.81(0.61,1.08)$ & & $0.84(0.63,1.10)$ & \\
\hline Age, years & & $0.796^{\#}$ & & $0.922^{\#}$ \\
\hline $18-30$ & 1.00 & & 1.00 & \\
\hline $31-59$ & $0.94(0.73,1.21)$ & & $1.11(0.83,1.48)$ & \\
\hline $60+$ & $0.85(0.50,1.44)$ & & $0.93(0.55,1.57)$ & \\
\hline Skin color & & 0.837 & & 0.947 \\
\hline White & 1.00 & & 1.00 & \\
\hline Non-white & $1.04(0.69,1.57)$ & & $1.01(0.68,1.52)$ & \\
\hline Highest educational achievement & & $0.016^{\#}$ & & $0.016^{\#}$ \\
\hline High school or less & 1.00 & & 1.00 & \\
\hline University & $0.82(0.61,1.11)$ & & $0.82(0.61,1.11)$ & \\
\hline Specialization, Master, $\mathrm{PhD}$ & $0.72(0.54,0.95)$ & & $0.72(0.54,0.95)$ & \\
\hline Conjugal status & & 0.450 & & 0.618 \\
\hline With partner & 1.00 & & 1.00 & \\
\hline No partner & $1.10(0.86,1.41)$ & & $1.06(0.83,1.36)$ & \\
\hline Region & & 0.625 & & 0.762 \\
\hline Sul & 1.00 & & 1.00 & \\
\hline Centro-Oeste & $0.94(0.64,1.38)$ & & $0.98(0.66,1.40)$ & \\
\hline Norte & $0.80(0.31,2.04)$ & & $1.00(0.40,2.49)$ & \\
\hline Missioneira & $0.53(0.16,1.83)$ & & $0.54(0.15,1.93)$ & \\
\hline Metropolitana & $1.12(0.91,1.39)$ & & $1.11(0.89,1.37)$ & \\
\hline Vales & $0.76(0.39,1.49)$ & & $0.75(0.39,1.44)$ & \\
\hline Serra & $0.75(0.36,1.57)$ & & $0.78(0.38,1.63)$ & \\
\hline Reduced monthly income & & 0.002 & & 0.003 \\
\hline No & 1.00 & & 1.00 & \\
\hline Yes & $1.46(1.14,1.85)$ & & $1.44(1.13,1.83)$ & \\
\hline Routine & & 0.052 & & 0.024 \\
\hline Low & $0.72(0.53,0.99)$ & & $0.72(0.53,0.98)$ & \\
\hline Medium & 1.00 & & 1.00 & \\
\hline High & $0.63(0.43,0.93)$ & & $0.60(0.41,0.87)$ & \\
\hline
\end{tabular}

common reason. Alongside the greater risk to severe outcomes in the case of COVID- $19^{4}$, the general orientation to stay home and misjudgment from the need of healthcare assistance as not urgent, are some factors that may be associated with such findings. Nevertheless, these health conditions have distinct characteristics and healthcare needs, so the outcome to decline in-person medical assistance might worse increasing symptoms and potentially aggravate the health status for this expressive group in our population ${ }^{36}$. Strategies and actions are warrant- ed to inform the population about the possible harmful effects of avoiding seeking healthcare assistance, and how to seek health services with safety, to minimize the risk of aggravated health conditions, especially during COVID-19 pandemic.

The present study has some limitations that must be acknowledged. First, our ambispective longitudinal design may lead to recall bias. Nevertheless, the unprecedented impact of COVID-19 pandemic on daily activities may be favorable to improve participants' ability to compare the 


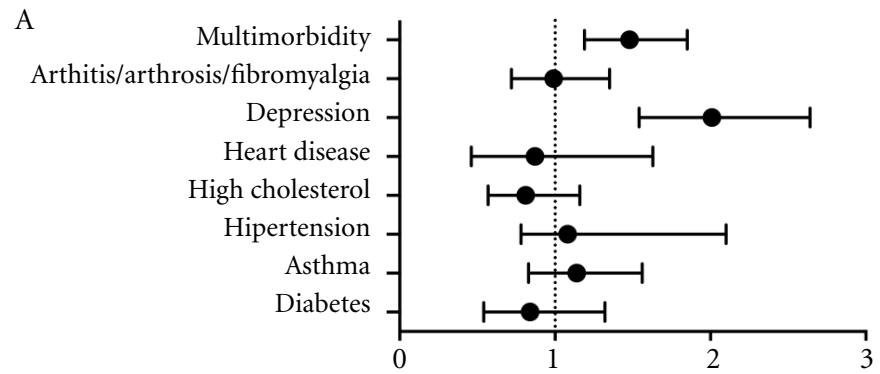

B

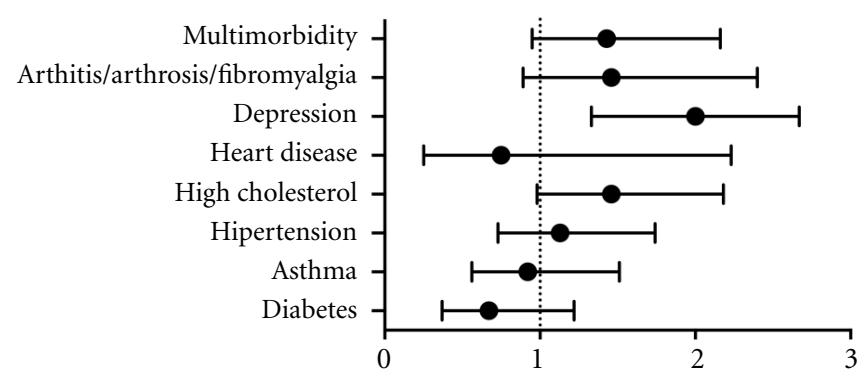

C

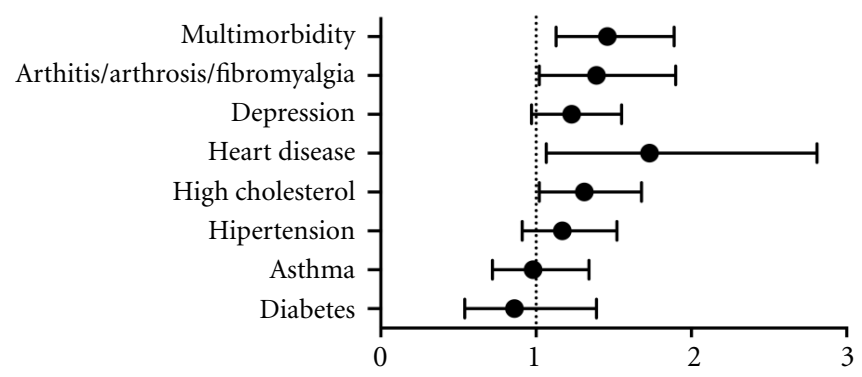

Figure 2. Prevalence ratio (95\%CI) between (A) impaired management of noncommunicable diseases, (B) impaired access to prescribed medicines, and $(C)$ avoid seeking healthcare, with independent variables in adults with chronic diseases. Rio Grande do Sul, Brazil, 2020 (N=1,288).

Adjusted for: sex, age, skin color, conjugal status, highest educational achievement, region, daily routine during social distancing, economic impact of COVID-19 pandemic. 95\%CI crossing dashed line indicate non-significant association ( $\mathrm{p} \geq 0.05)$.

moments before and during social distancing restrictions. Second, as face-to-face data collection was not allowed by the ethics board, a probabilistic sampling process was not possible, increasing the selection bias. However, participants included in this study had similar demographic characteristics to the general population of the Rio Grande do Sul state ${ }^{37}$, improving our external validity. Lastly, the questionnaire was self-adminis- tered which may be more prone to response bias. Nevertheless, as previously reported ${ }^{38}$, self-report scales might be useful in the current scenario as they are usually short, easy to administer, and feasible to be used in social distancing. Notwithstanding the abovementioned limitations, we must highlight as strength from this present study its novelty aspect. To the moment this paper was written, no population-based study in Brazil 
that aimed to identify the susceptible groups to worse NCD management during the COVID-19 pandemic was published. Then, our results contribute to highlight the high prevalence of NCD among younger adults and with a high level of education in Rio Grande do Sul state. Moreover, younger adults need equal attention to improve your health condition as older adults and elderly with NCD.

\section{Conclusion}

During the COVID-19 pandemic we demonstrated that many people with NCD had impaired management of their diseases, impaired access to prescribed medication, and many avoided seeking healthcare. These disruptions may have both immediate and long-term deleterious effects on the health of the individuals. Actions are need to be preserve the health of people living with NCDs in these difficulties times of pandemic.

\section{Collaborations}

JS Leite, N Feter, EL Caputo, IR Doring, J Cassuriaga, FF Reichert, MC Silva and AJ Rombaldi: conceptualization, methodology. JS Leite and $\mathrm{N}$ Feter: data curation, data analysis, writing, original draft preparation. FF Reichert, MC Silva and AJ Rombaldi: supervision. EL Caputo, IR Doring, J Cassuriaga, FF Reichert, MC Silva and AJ Rombaldi: writing, reviewing and editing. 


\section{References}

1. World Health Orzanization (WHO). Noncommunicable diseases country profiles. Geneva: WHO; 2018.

2. Nilson EAF, Andrade RCS, Brito DA, Oliveira ML. Custos atribuíveis a obesidade, hipertensão e diabetes no Sistema Único de Saúde, Brasil, 2018. Rev Panam Salud Pública 2020; 44:e32.

3. Malta DC, Bernal RTI, Lima MG, Araújo SSC, Silva MMA, Freitas MIF, Barros MBA. Doenças crônicas não transmissíveis e a utilização de serviços de saúde: análise da Pesquisa Nacional de Saúde no Brasil. Rev Saude Publica 2017; 51(Supl. 1):4s.

4. Zhou Y, Yang Q, Chi J, Dong B, Lv W, Shen L, Wang Y. Comorbidities and the risk of severe or fatal outcomes associated with coronavirus disease 2019: A systematic review and meta-analysis. Int $J$ Infect Dis 2020; 99:47-56.

5. Dyer O. Covid-19: Pandemic is having "severe" impact on non-communicable disease care, WHO survey finds. BMJ 2020; 369:m2210.

6. Islam N, Sharp SJ, Chowell G, Shabnam S, Kawachi I, Lacey B, Massaro JM, D’Agostino Sr RB, White M. Physical distancing interventions and incidence of coronavirus disease 2019: natural experiment in 149 countries. BMJ 2020; 370:m2743.

7. Paules CI, Marston HD, Fauci AS. Coronavirus Infections-More Than Just the Common Cold. JAMA 2020; 323(8):707-708.

8. Landmann-Szwarcwald C, Macinko J. A panorama of health inequalities in Brazil. Int J Equity Health 2016; 15(1):1-3.

9. Sohrabi C, Alsafi Z, O’Neill N, Khan M, Kerwan A, Al-Jabir A, Iosifidis C, Agha R. World Health Organization declares global emergency: A review of the 2019 novel coronavirus (COVID-19). Int J Surg 2020; 76:71-76.

10. World Heath Organization (WHO). Pulse survey on continuity of essential health services during the COVID-19 pandemic: interim report, 27 August 2020. Geneva: WHO; 2020.

11. Feter N, Caputo EL, Doring IR, Leite JS, Cassuriaga J, Reichert FF, Silva MC, Rombaldi AJ. Longitudinal study about low back pain, mental health, and access to healthcare system during COVID-19 pandemic: protocol of an ambispective cohort Short title: PAMPA cohort: study protocol. medRxiv 2020. doi: https:// doi.org/10.1101/2020.07.22.20160309.

12. Enes CC, Nucci LB. A Telephone Surveillance System for Noncommunicable Diseases in Brazil. Public Health Rep 2019; 134(4):324-327.

13. World Health Organization (WHO). Multimorbidity: Technical Series on Safer Primary Care. Geneva: WHO; 2016.

14. Centers for Disease Control and Prevention (CDC). Defining adult overweight and obesity [Internet]. 2016 [acessado 2020 Set 9]. Disponível em: https://www. cdc.gov/obesity/adult/defining.html

15. World Health Organization (WHO). Global recommendations on Physical Activity for health. Geneva: WHO; 2010;

16. Wenham C, Smith J, Morgan R. COVID-19: the gendered impacts of the outbreak. Lancet 2020; 395(10227):846-848.
17. United Nations (UN). COVID-19 and the Need for Action on Mental Health [Internet]. 2020 [acessado 2020 Set 9]. Disponível em: https://unsdg.un.org/ resources/policy-brief-covid-19-and-need-actionmental-health

18. Mássimo EAL, Souza HNF, Freitas MIF. Doenças crônicas não transmissíveis, risco e promoção da saúde: construções sociais de participantes do Vigitel. Cien Saude Colet 2015; 20(3):679-688.

19. Estado do Rio Grande do Sul. Decreto $\mathrm{n}^{\circ}$ 55.240, de 10 de maio de 2020. Institui o Sistema de Distanciamento Controlado para fins de prevenção e de enfrentamento à epidemia causada pelo novo Coronavírus (COVID-19) no âmbito do Estado do Rio Grande do Sul, reitera a declaração de estado de calamidade pública em todo o território estadual e dá outras providências. Diário Oficial do Estado; 2020.

20. Warburton DER, Bredin SSD. Health benefits of physical activity: A strengths-based approach. J Clin Med 2019; 8(12):2044.

21. Dohrn M, Welmer A-K, Hagströmer M. Accelerometry-assessed physical activity and sedentary time and associations with chronic disease and hospital visits-a prospective cohort study with 15 years follow-up. Int J Behav Nutr Phys Act 2019; 16(1):125.

22. Bowden Davies KA, Pickles S, Sprung VS, Kemp GJ, Alam U, Moore DR, Tahrani AA, Cuthbertson DJ. Reduced physical activity in young and older adults: metabolic and musculoskeletal implications. Ther $A d v$ Endocrinol Metab 2019; 10:2042018819888824.

23. Bielemann RM, Silva BGC, Coll CVN, Xavier MO, Silva SG. Impacto da inatividade física e custos de hospitalização por doenças crônicas. Rev Saude Publica 2015; 49(75):1-8.

24. Stopa SR, Malta DC, Oliveira MM, Lopes CS, Menezes PR, Kinoshita RT. Prevalência do autorrelato de depressão no Brasil: resultados da Pesquisa Nacional de Saúde, 2013. Rev Bras Epidemiol 2015; 18:170-180.

25. Tull MT, Edmonds KA, Scamaldo K, Richmond JR, Rose JP, Gratz KL. Psychological Outcomes Associated with Stay-at-Home Orders and the Perceived Impact of COVID-19 on Daily Life. Psychiatry Res 2020; 113098.

26. Ornell F, Schuch JB, Sordi AO, Kessler FHP. "Pandemic fear" and COVID-19: mental health burden and strategies. Brazilian J Psychiatry 2020; 42(3):232-235.

27. Clark A, Jit M, Warren-Gash C, Guthrie B, Wang HHX, Mercer SW, Sanderson C, McKee M, Troeger C, Ong KL, Checchi F, Perel P, Joseph S, Gibbs HP, Banerjee A, Eggo RM, Centre for the Mathematical Modelling of Infectious Diseases COVID-19 working group. Global, regional, and national estimates of the population at increased risk of severe COVID-19 due to underlying health conditions in 2020: a modelling study. Lancet Glob Heal 2020; 8(8):e1003-e1017.

28. Iaccarino G, Grassi G, Borghi C, Ferri C, Salvetti $\mathrm{M}$, Volpe M. Age and multimorbidity predict death among COVID-19 patients: results of the SARS-RAS study of the Italian Society of hypertension. Hypertension 2020; 76(2):366-372. 
29. Chudasama Y V, Gillies CL, Zaccardi F, Coles B, Davies MJ, Seidu S, Khunti K. Impact of COVID-19 on routine care for chronic diseases: A global survey of views from healthcare professionals. Diabetes Metab Syndr 2020; 14(5):965-967.

30. Caetano R, Silva AB, Guedes ACCM, Paiva CCN, Ribeiro GR, Santos DL, Silva RM. Challenges and opportunities for telehealth during the COVID-19 pandemic: ideas on spaces and initiatives in the Brazilian context. Cad Saude Publica 2020; 36:e00088920.

31. Fernandes N. Economic effects of coronavirus outbre$\mathrm{ak}$ (COVID-19) on the world economy. IESE Business School Working Paper No. WP-1240-E 2020; 1-33.

32. Zhang SX, Wang Y, Rauch A, Wei F. Unprecedented disruption of lives and work: Health, distress and life satisfaction of working adults in China one month into the COVID-19 outbreak. Psychiatry Res 2020; 112958.

33. Tavares NUL, Costa KS, Mengue SS, Vieira MLFP, Malta DC, Silva Júnior JB. Uso de medicamentos para tratamento de doenças crônicas não transmissíveis no Brasil: resultados da Pesquisa Nacional de Saúde, 2013. Epidemiol Serv Saúde 2015; 24:315-323.

34. World Health Organization (WHO). Global action plan for the prevention and control of noncommunicable diseases 2013-2020. Geneva: WHO; 2013.

35. Lopes CS, Hellwig N, Silva GA, Menezes PR. Inequities in access to depression treatment: results of the Brazilian National Health Survey-PNS. Int J Equity Health 2016; 15(1):154.

36. Pachiega J, Afonso AJS, Sinhorin GT, Alencar BT, Araújo MSM, Longhi FG, Zanetti AS, Espinosa OA. Chronic heart diseases as the most prevalent comorbidities among deaths by COVID-19 in Brazil. Rev Inst Med Trop Sao Paulo 2020; 62:e45.

37. Instituto Brasileiro de Geografía e Estatística (IBGE). Censo demográfico 2010 [Internet]. 2010 [acessado 2020 Out 3]. Disponível em: https://censo2010.ibge. gov.br/

38. Ransing R, Ramalho R, Orsolini L, Adiukwu F, Gonzalez-Diaz JM, Larnaout A, Costa MP, Grandinetti P, Bytyçi DG, Shalbafan M, Patil I, Nofal M, Pereira-Sanchez V, Kilic O. Can COVID-19 related mental health issues be measured? Brain Behav Immun 2020; 88:3234.

Article submitted 21/10/2020

Approved 18/11/2020

Final version submitted 20/11/2020

Chief Editors: Romeu Gomes, Antônio Augusto Moura da Silva 